\title{
Ruthenium-Catalyzed Enantioselective Reductive Amination
}

\section{Key words}

ruthenium catalysis reductive amination

asymmetric synthesis

\section{Synfact
of the Month}

Significance: The authors report a rutheniumcatalyzed reductive amination of ketones.

$\mathrm{Ru}-(\mathrm{OAc})_{2}((\mathrm{~S})$-binap) is used as catalyst and ammonium trifluoroacetate as the nitrogen source; hydrogen pressures of $0.8 \mathrm{MPa}$ are needed. The procedure allows the formation of chiral amines in high enantiomeric excess and quantitative conversions. Sensitive functional groups such as esters and amides are tolerated.
Comment: Reductive aminations are widespread reactions in the pharmaceutical industry. This direct asymmetric reductive amination allows for the generation of chiral secondary amines from ketones, which has been challenging before. Diarylketones, fused ring ketones, and 2-acetyl-6-pyridone showed no reaction under these conditions 